\title{
Accessing Confidential Health Information by Mobile Devices the Trend of Online Treatment and Use of Social Media for Health Services
}

\author{
Dr Ahsan Siddiqui, M.D, M.S.P.H (UK)* \\ Quality Management \& Patient Safety Department, General Directorate of Health, Saudi Arabia
}

*Corresponding author: Dr Ahsan Ali Siddiqui, Consultant Epidemiologist, Quality Management \& Patient Safety Department,

General Directorate of Health, Riyadh Saudi Arabia, Email: drahsan77@hotmail.com

\section{ARTICLE INFO}

Received: 幽 February 25, 2019

Published: March 12, 2019

Citation: Ahsan Ali Siddiqui. Accessing Confidential Health Information by Mobile Devices the Trend of Online Treatment and Use of Social Media for Health Services. Biomed J Sci \& Tech Res 15(5)-2019. BJSTR. MS.ID.002765.

Keywords: Cell phones; Electronic mail; Health information exchange; Mobile health; Patient/consumer attitudes

\section{ABSTRACT}

Background and Objective: This Article themed to provide idea that people in Favor or against the use of Mobile Phones Internet and Gadgets to obtain Health services.

Methods: Literature Review and Critical Analysis of the 12 Articles to complete the Argument in the Article. Comparative Study and Review of the 8 Articles provided in the Table that Authors Conclusion in Favor or against the use of Mobile Phone and Internet in Health Services.

Results: From 6 out of 8 Pubmed Published Journal Articles Concludes in Favor of use of Social media and Online accessing Health Information and taking Online Treatment with 2 Articles in Against.

Conclusion: Data Table and Data Analysis clearly provides that $75 \%$ out of $100 \%$ of the selected Articles Authors Opinion agreed in Favor of use of Social media and Online accessing Health Information and taking Online Treatment.

\section{Introduction}

The rapid proliferation of mobile devices offers unprecedented opportunities for patients and health care professionals to exchange health information electronically, but little is known about patients' willingness to exchange various types of health information using these devices. Article examined willingness to exchange different types of health information via mobile devices and assessed whether sociodemographic characteristics and trust in clinicians were associated with willingness in a nationally representative sample [1]. There is considerable potential for mobile technologies to empower pediatric patients and families by improving their communication with health professionals. National surveys suggest minority parents frequently communicate via mobile technology, but it is uncertain how amenable they are to receiving health care information in this format. Although the low cost and far reach characteristics of mobile health (mHealth) technology make it advantageous for communication with minority parents, data on acceptance are needed [2]. Little research exists about adolescents' and young adults' use of new media technologies to communicate about sexual health [3]. Understanding how young people at high risk for STDs use these technologies can inform media-based interventions. To promote sexual health among adolescents and young adults, many health organizations are turning to new media for example the Internet, social networking sites and mobile phones to disseminate information and stimulate conversations about health topics.

This innovative approach to health communication has the potential to reach a large audience and trigger dialogue about sexual health attitudes and norms. However, little research exists to inform the design of such interventions. To create an effective, new media-based intervention to promote sexual health, it is essential to understand how adolescents and young adults use new media. Between October 2010 and March 2011, a sample of 94 
low-income, parenting adolescents and young adults recruited at clinics in Connecticut completed an audio computer-assisted selfinterview about their use of media technologies, communication with friends about sexual health and willingness to use media technologies for such communication. Descriptive statistics were calculated; characteristics of those willing and those unwilling to communicate were compared in chi-square, $\mathrm{t}$ and Mann-Whitney tests. For conversations about sexual health, young urban parents prefer private forms of communication; thus, social networking sites may not aid STD interventions [3]. Young adults often lack access to confidential, long-lasting, and nonjudgmental interactions with sexual health professionals at brick-and-mortar clinics [4].

To ensure that patients return for their STI test results, post-result counseling, and STI-related information, computer-mediated health intervention programming allows them to receive sexual health information through onsite computers, the Internet, and mobile phone calls and text messages. To determine whether young adults (age: $\mathrm{M}=21$ years) prefer to communicate with health professionals about the status of their sexual health through computer-mediated communication devices, 303 second-year university students (183 from an urban North American university and 120 from a peri urban university in South Africa) completed a paper-based survey indicating how they prefer to communicate with doctors and nurses: talking face to face, mobile phone call, text message, Internet chat programs, Facebook, Twitter, or e-mail. Nearly all students and female students in South Africa in particular, prefer to receive their STI test results, post-results counseling, and STI-related information by talking face to face with doctors and nurses rather than communicating through computers or mobile phones [4]. Results are clarified in relation to gender, availability of various technologies, and prevalence of HIV in Canada and in South Africa.

\section{Methods}

Author of This Article has selected a literature review of 8 Published Articles. Two types of literature were reviewed includes guidance and published studies [5]. Seven guidance documents were identified, including Journal of Medical Internet Research, Journal of Health Communication International Perspectives and Perspectives on Sexual and Reproductive Health Others. Published studies were identified through a search of PubMed using the systematic review methods filter, and the authors' topic knowledge. The relevant sections within each guidance document were then read and re-read, with the aim of determining key methodological stages. Methodological stages were identified and defined. This data was reviewed to identify agreements and areas of unique guidance between guidance documents. Consensus across multiple guidance documents was used to inform selection of 'key stages' in the process of literature searching. Systematic literature searching is recognized as a critical component of the systematic review process. It involves a systematic search for studies and aims for a transparent report of study identification, leaving readers clear about what was done to identify studies, and how the findings of the review are situated in the relevant evidence. Information specialists and review teams appear to work from a shared and tacit model of the literature search process [5]. How this tacit model has developed and evolved is unclear, and it has not been explicitly examined before.

Nowadays, most nurses' pre and post-qualification will be required to undertake a literature review at some point [6]. Either as part of a course of study as a key step in the research process or as part of clinical practice development or policy. For student nurses and novice researchers it is often seen as a difficult undertaking. It demands a complex range of skills, such as learning how to define topics for exploration, acquiring skills of literature searching and retrieval, developing the ability to analyze and synthesize data as well as becoming adept at writing and reporting, often within a limited time scale [6]. The purpose of this article is to present a step-by-step guide to facilitate understanding by presenting the critical elements of the literature review process. While reference is made to different types of literature reviews, the focus is on the traditional or narrative review that is undertaken, usually either as an academic assignment or part of the research process. This article examines how to synthesize and critique research literature [7]. To place the process of synthesizing the research literature into context, the article explores the critiquing process by breaking it down into seven sequential steps. The article explains how and why these steps need to be kept in mind if a robust comprehensive literature search and analysis are to be achieved [7].

The article outlines how to engage in the critiquing process and explains how the literature review needs to be assembled to generate a logical and reasoned debate to examine a topic of interest or research in more detail. A systematic literature review was conducted by searching the Pubmed and Web of Science databases for articles with the following keywords in their titles or abstracts [8]: "Analytic Hierarchy Process," "Analytical Hierarchy Process," "multi-criteria decision analysis," "multiple criteria decision," "stated preference" and "pairwise comparison". In addition, we developed reporting criteria to indicate whether the authors reported important aspects and evaluated the resulting studies' reporting. The systematic review resulted in 121 articles and the number of studies applying AHP has increased since 2005. Most studies were from Asia (almost $30 \%$ ), followed by the US (25.6\%). On average the studies used 19.64 criteria throughout their hierarchical levels. Furthermore, we restricted a detailed analysis to those articles published within the last 5 years $(n=69)$ [8]. The mean of participants in these studies were 109, whereas we identified major differences in how the surveys were conducted. The evaluation of reporting showed that the mean of reported elements was about 6.75 out of 10 . Thus, 12 out of 69 studies reported less than half of the criteria (Table 1 ). 
Table 1: Literature Review of 8 Published Articles and their Conclusion in favor OR against use of Social media and Online accessing Health Information and taking Online Treatment.

\begin{tabular}{|c|c|c|}
\hline \multicolumn{3}{|c|}{$\begin{array}{c}\text { Literature Review of } 8 \text { Published Articles and their Conclusion in favor OR against use of Social media and Online accessing Health Informa- } \\
\text { tion and taking Online Treatment }\end{array}$} \\
\hline \multicolumn{2}{|r|}{ Articles } & \multirow{2}{*}{$\begin{array}{c}\text { Conclusion } \\
\text { Against }\end{array}$} \\
\hline 1 & $\begin{array}{l}\text { Serrano KJ, Yu M, Riley WT, Patel V, Hughes P, Marchesini K, And Atienza AA. (2016) Willingness to Exchange Health Informa- } \\
\text { tion via Mobile Devices: Findings from a Population-Based Survey. Annals of Family Medicine 14(1): 34-40. }\end{array}$ & \\
\hline 2 & $\begin{array}{l}\text { Journal of Medical Internet Research (2018) Internet and Mobile Technology Use among Urban African American Parents: } \\
\text { Survey Study of a Clinical Population. }\end{array}$ & In Favor \\
\hline 3 & $\begin{array}{l}\text { Divecha Z, Divney A and Ickovics J (2012) Tweeting About Testing: Do Low-Income, Parenting Adolescents and Young Adults } \\
\text { Use New Media Technologies to Communicate About Sexual Health? Perspectives on Sexual and Reproductive Health } 44 \text { (3): } \\
\text { 176- } 183 \text {. }\end{array}$ & Against \\
\hline 4 & $\begin{array}{l}\text { Labacher L and Mitchel C (2013) Talk or Text to Tell? How Young Adults in Canada and South Africa Prefer to Receive STI } \\
\text { Results, Counseling, and Treatment Updates in a Wireless World. Journal of Health Communication International Perspectives } \\
18(12): 1465-1476 .\end{array}$ & In Favor \\
\hline 5 & $\begin{array}{c}\text { Roettl J, Bidmon S, and Terlutter R (2016) What Predicts Patients' Willingness to Undergo Online Treatment and Pay for } \\
\text { Online Treatment? Results from a Web-Based Survey to Investigate the Changing Patient-Physician Relationship. Journal of } \\
\text { Medical Internet Research. 18(2): e32. }\end{array}$ & In Favor \\
\hline 6 & $\begin{array}{l}\text { Genz A, Kirk G, Piggott D, Mehta SH, Linas BS, and Westergaard RP (2015) Uptake and Acceptability of Information and Com- } \\
\text { munication Technology in a Community-Based Cohort of People Who Inject Drugs: Implications for Mobile Health Interven- } \\
\text { tions. JMIR Mhealth Uhealth. 3(2): e70. }\end{array}$ & In Favor \\
\hline 7 & $\begin{array}{c}\text { Holloway IW, Winder TJ, Lea CH III, Tan D, Boyd D, and Novak D (2017) Technology Use and Preferences for Mobile Phone- } \\
\text { Based HIV Prevention and Treatment Among Black Young Men Who Have Sex with Men: Exploratory Research. JMIR Mhealth } \\
\text { Uhealth 5(4): e46. }\end{array}$ & In Favor \\
\hline 8 & $\begin{array}{l}\text { Finkelstein J, And Cha EM (2016) Using a Mobile App to Promote Smoking Cessation in Hospitalized Patients. JMIR Mhealth } \\
\text { Uhealth 4(2): e59. }\end{array}$ & In Favor \\
\hline & $\begin{array}{c}\text { out of } 8 \text { Pubmed Published Journal Articles Concludes in Favor of use of Social media and Online accessing Health Inform } \\
\text { Online Treatment with } 2 \text { Articles in Against. }\end{array}$ & d taking \\
\hline
\end{tabular}

Measures and Statistical Analysis: (Figures 1-3).

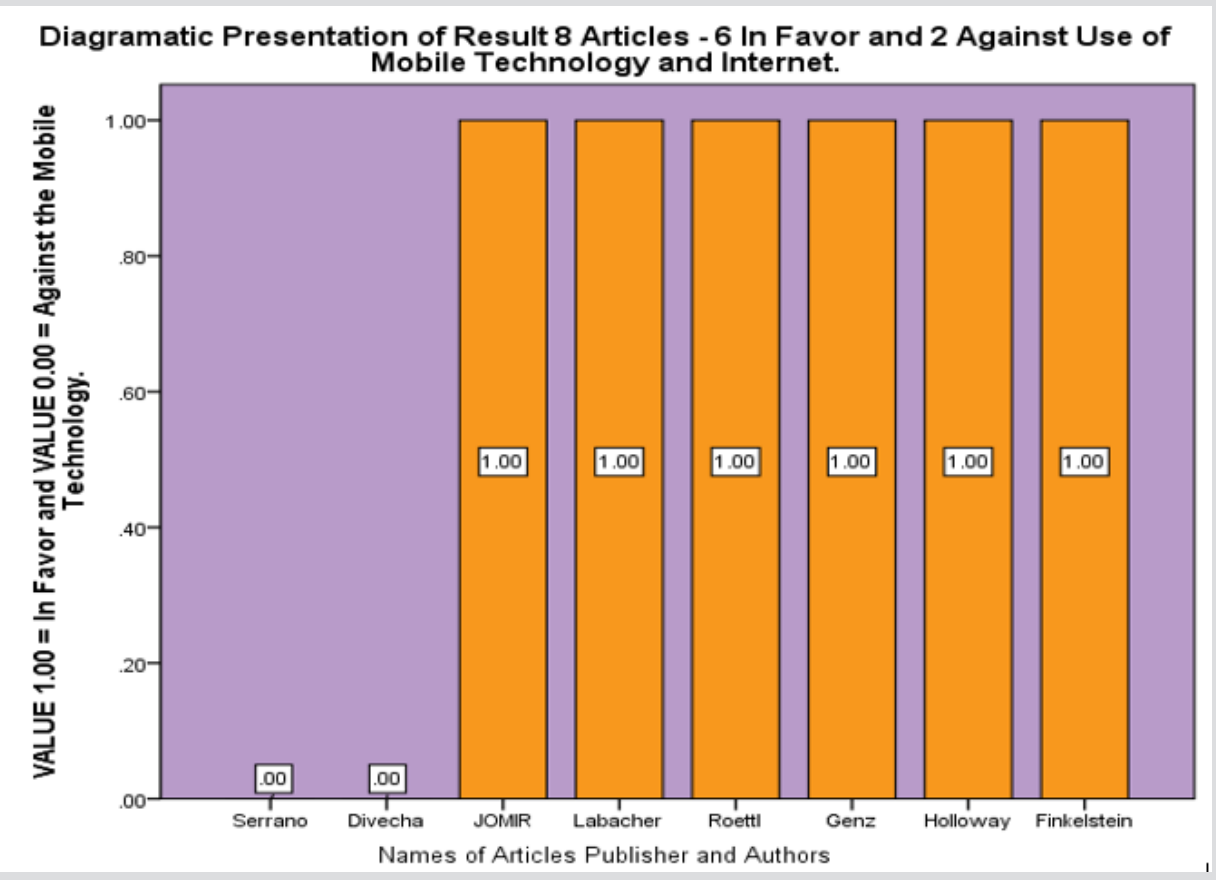

Figure 1: Diagrammatic presentation of result 8 articels- 6 in favour and 2 against use of mobile technology and internet. 


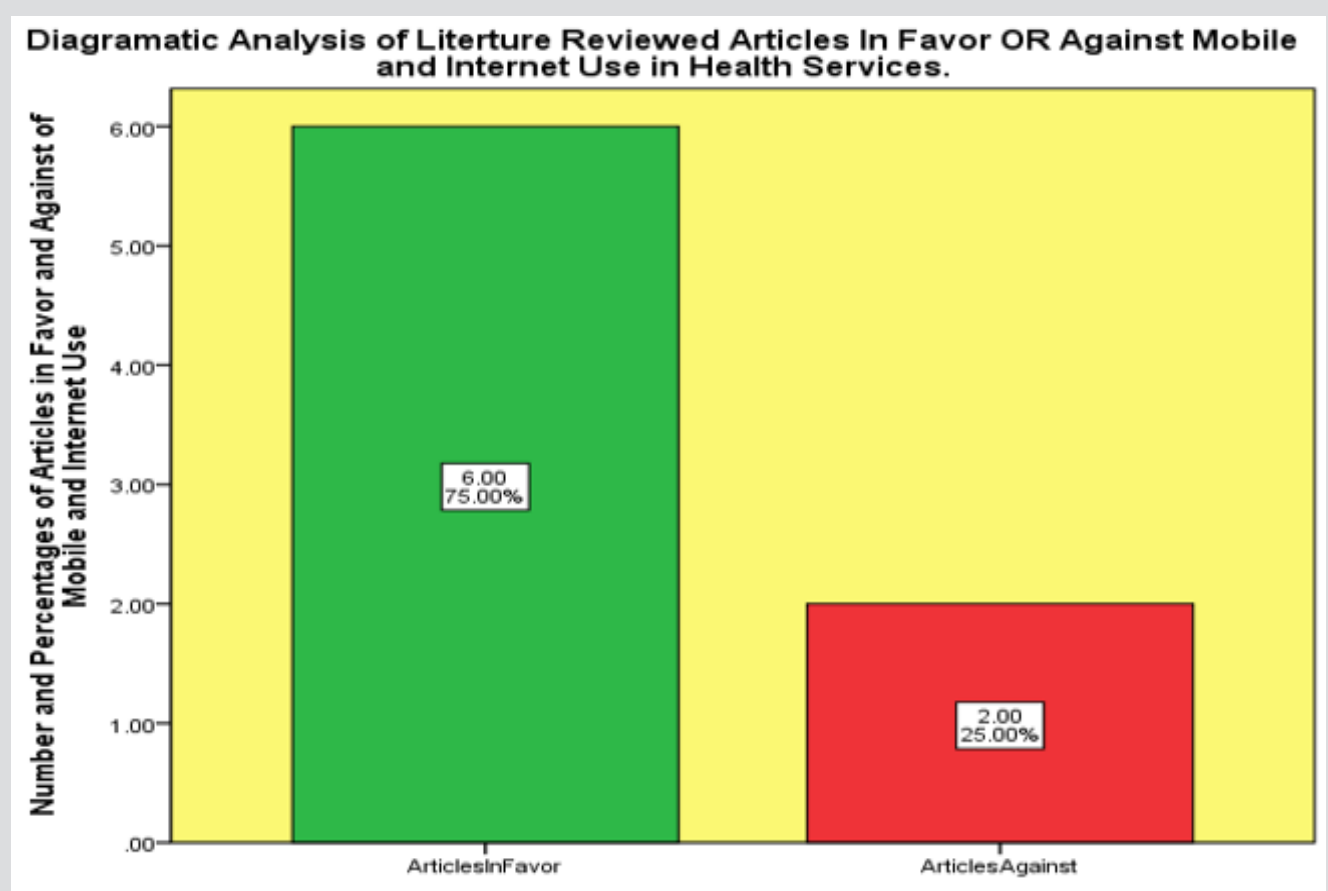

Figure 2: Diagrammatic analysis of literature reviewed articles in favour or against mobile and internet use in health services.

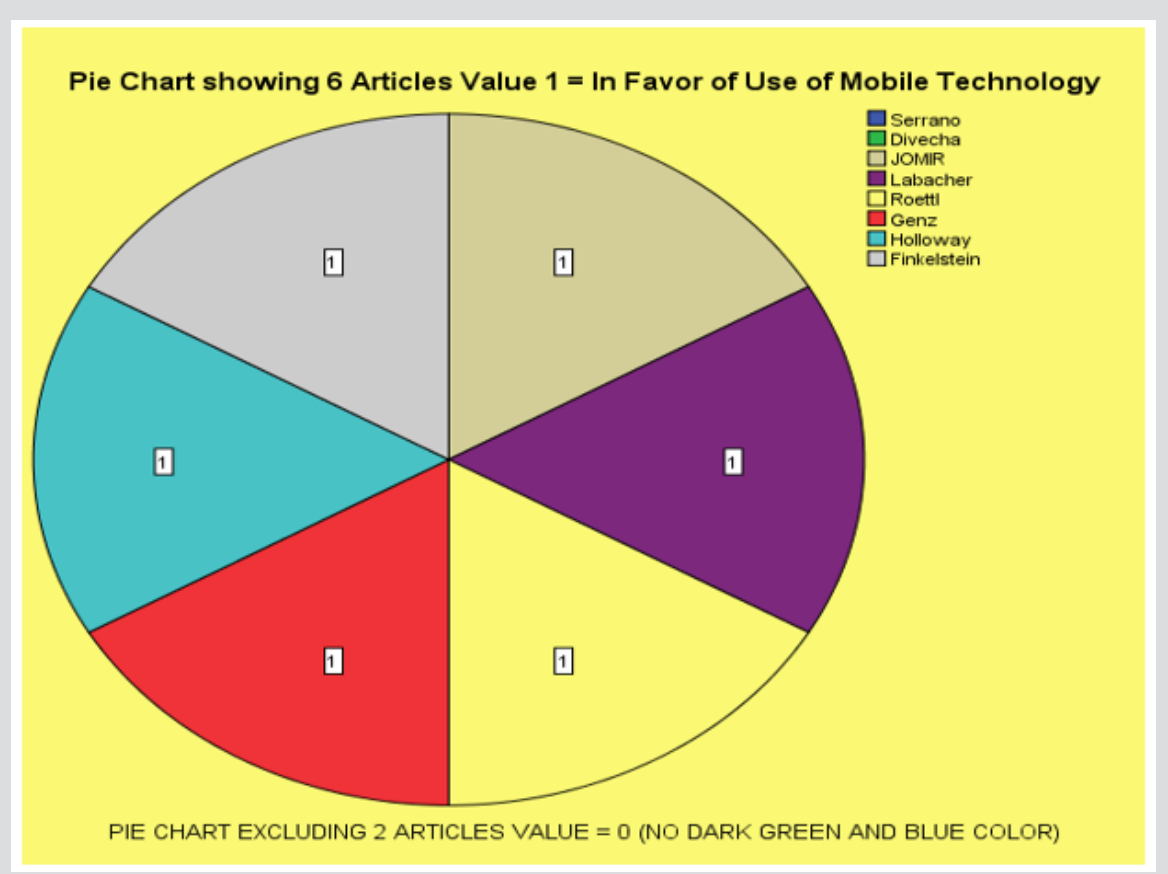

Figure 3: Pie chart showing 6 articles value 1=in favour of use of mobile technology.

\section{Results}

To understand patterns of mobile phone ownership, Internet use and willingness to receive health information via mobile devices among people who inject drugs [9]. We surveyed current and former drug injectors participating in a longitudinal cohort study in Baltimore, Maryland, USA. Respondents completed a 12- item, interviewer-administered questionnaire during a regular semi-annual study visit that assessed their use of mobile technology and preferred modalities of receiving health information. Using data from the parent study, we used logistic regression to evaluate associations among participants' demographic and clinical characteristics and their mobile phone and Internet use. Our 
findings identify a potential barrier to successful implementation of mobile health and Internet-based interventions for people who inject drugs, particularly those who are older and have lower levels of income and educational attainment [9]. As mobile communication technology continues to expand, future studies should re-examine whether mHealth applications become more accessible and accepted by socioeconomically disadvantaged groups.

Black young men who have sex with men (BYMSM) experience higher human immunodeficiency virus (HIV) incidence than their white and Latino counterparts [10]. The aim of our study was to understand BYMSM's preferences for mobile phone-based HIV prevention and treatment in order to inform culturally tailored interventions to reduce the spread of HIV and improve HIV treatment outcomes in this population. Qualitative focus groups $(\mathrm{N}=6)$ with BYMSM aged 18-29 years ( $\mathrm{N}=41 ; 46 \%, 19 / 41$ HIV-positive) were conducted to elucidate their preferences for the design and delivery of mobile phone-based HIV prevention and treatment interventions. A modified grounded theory approach to data analysis was undertaken using ATLAS.ti textual analysis software. Participants preferred holistic health interventions that did not focus exclusively on HIV prevention and treatment. Issues of privacy and confidentiality were paramount. Participants preferred functionality that enables discreet connections to culturally competent health educators and treatment providers who can address the range of health and psychosocial concerns faced by BYMSM.

Mobile phone-based HIV prevention has the potential to increase engagement with HIV prevention and treatment resources among BYMSM [10]. For these approaches to be successful, researchers must include BYMSM in the design and creation of these interventions. The potential of interactive health education for preventive health applications has been widely demonstrated [11]. However, use of mobile apps to promote smoking cessation in hospitalized patients has not been systematically assessed. We conducted study and Fifty-five consecutive hospitalized smokers were recruited. Patient sociodemographic and smoking history was collected at baseline. The impact of the mobile app was assessed by measuring cognitive and behavioral factors shown to promote smoking cessation before and after the mobile app use including hazards of smoking knowledge score (KS), smoking attitudes, and stages of change. Our results suggest that a mobile app promoting smoking cessation is well accepted by hospitalized smokers [11]. The app can be used for interactive patient education and counseling during hospital stays. Development and evaluation of mobile apps engaging patients in their care during hospital stays is warranted.

\section{Discussions}

Respondents were less willing to exchange via mobile devices information that may be considered sensitive or complex [1]. Age, socioeconomic factors, and trust in professional information were associated with willingness to engage in mobile health information exchange. Both information type and demographic group should be considered when developing and tailoring mobile technologies for patient-clinician communication [1]. For conversations about sexual health young urban parents prefer private forms of communication thus social networking sites may not aid STD interventions [3]. The use of the Internet as a source of health information by patients has increased rapidly in many Western societies within the last few years [12]. An increasing number of people want to gain a more collaborative view of their own health and use the Internet as an aid to self-diagnosis and self-medication, which leads to the "empowered patient". In the past, the physician typically held the majority of the information and power and provided the patient with selected information.

Now, because patients have access to an enormous quantity of health-related information through the Internet, the asymmetry of information in the patient-physician relationship is decreasing [12]. A national survey conducted by the Pew Internet \& American Life Project in 2013 showed that $72 \%$ of US adults who use the Internet have searched online for health-related information (representing 59\% of all US adults). More than one-quarter (28\%) base their decision about whether or not to visit a physician on online health-related information. Most US adults (70\%) use the Internet primarily to obtain health-related information to inform themselves and/or to change their decision about a treatment for their illness, whereas half of US adults (50\%) use the Internet to find answers to specific health-related questions or to get different opinions from other physicians or Internet users. From a demographic point of view, women are more prone to searching for health-related information than men, and younger people use the Internet to obtain health-related information more often than older individuals do [12]. In the United States, Internet users between the ages of 30 and 64 years are the most likely group to consult or post online reviews and rankings of health treatments and services.

Furthermore, Internet users with a higher level of education are more likely to consult or post online health-related reviews and rankings in comparison to those with a lower level of education. The same is true for people with a higher annual household income compared to those with a lower annual household income. Age, gender, and trust in the GP were not significant predictors for either willingness to undergo online treatment or to pay additionally for online treatment [12]. Willingness to undergo online treatment was partly determined by the actual use of online communication with the GP, willingness to communicate online with the GP, health information-seeking personality, and social motivation for such behavior. Willingness to pay extra for online treatment was influenced by the monthly household net income category and education level. The results of this study are useful for online health care providers 
and physicians who are considering offering online treatments as a viable number of patients would appreciate the possibility of undergoing an online treatment offered by their GP $[12,13]$.

\section{Conclusion}

Data Table and Data Analysis clearly provides that $75 \%$ out of $100 \%$ of the selected Articles Authors Opinion agreed in Favor of use of Social media and Online accessing Health Information and taking Online Treatment. From 6 out of 8 Pubmed Published Journal Articles Concludes in Favor of use of Social media and Online accessing Health Information and taking Online Treatment with 2 Articles in Against. The Literature Review of 8 Articles provides Message that use of Social media and Online accessing Health Information and taking Online Treatment are more acceptable and beneficial for the society. There are more of the Benefits as compare to Harmful effects use of Social media and Online accessing Health Information and taking Online Treatment. Internet and Computer Technology has made our life more comfortable and people could access Best Health recommendations and useful Health Knowledge on tip of Finger within few seconds.

\section{References}

1. Serrano KJ, Yu M, Riley WT, Patel V, Hughes P, et al. (2016) Willingness to Exchange Health Information via Mobile Devices: Findings from a Population-Based Survey. Annals of Family Medicine. 14(1): 34-40.

2. (2018) Internet and Mobile Technology Use among Urban African American Parents: Survey Study of a Clinical Population. Journal of Medical Internet Research.

3. Divecha Z, Divney A, Ickovics J, Kershaw T (2012) Tweeting About Testing: Do Low-Income, Parenting Adolescents and Young Adults

\section{ISSN: 2574-1241}

DOI: 10.26717/BJSTR.2019.15.002765

Dr Ahsan Ali Siddiqui. Biomed J Sci \& Tech Res

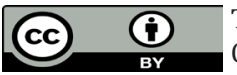

This work is licensed under Creative

Commons Attribution 4.0 License

Submission Link: https://biomedres.us/submit-manuscript.php
Use New Media Technologies to Communicate About Sexual Health? Perspectives on Sexual and Reproductive Health 44 (3): 176-183.

4. Labacher L and Mitchel C (2013) Talk or Text to Tell? How Young Adults in Canada and South Africa Prefer to Receive STI Results, Counseling, and Treatment Updates in a Wireless World. Journal of Health Communication International Perspectives. 18 (12): 1465-1476.

5. Cooper C, Booth A, Varley-Campbell J, Britten N (2018) Defining the process to literature searching in systematic reviews: a literature review of guidance and supporting studies. BMC Part of Springer Nature. 18(1): 85.

6. Cronin P, Ryan F, Coughlan M (2008) Undertaking a literature review: a step-by-step approach. BJN British Journal of Nursing 17(1): 38- 43.

7. Wakefield A (2015) Synthesizing the literature as part of a literature review. Nursing Standard 29(29): 44-51.

8. Katharina Schmidt, Ines Aumann, Ines Hollander, Kathrin Damm, J Matthias Graf von der Schulenburg (2015) Applying the Analytic Hierarchy Process in healthcare research: A systematic literature review and evaluation of reporting. BMC Medical Informatics and Decision Making 15: 112 .

9. Genz A, Kirk G, Piggott D, Mehta SH, Linas BS, et al. (2015) Uptake and Acceptability of Information and Communication Technology in a Community-Based Cohort of People Who Inject Drugs: Implications for Mobile Health Interventions. JMIR Mhealth Uhealth. 3(2): e70.

10. Holloway IW, Winder T], Lea CH III, Tan D, Boyd D, et al. (2017) Technology Use and Preferences for Mobile Phone-Based HIV Prevention and Treatment Among Black Young Men Who Have Sex with Men: Exploratory Research. JMIR Mhealth Uhealth 5(4): e46.

11. Finkelstein J, Cha EM (2016) Using a Mobile App to Promote Smoking Cessation in Hospitalized Patients. JMIR Mhealth Uhealth. 4(2): e59.

12. Roettl J, Bidmon S, Terlutter R (2016) What Predicts Patients' Willingness to Undergo Online Treatment and Pay for Online Treatment? Results from a Web-Based Survey to Investigate the Changing Patient-Physician Relationship. Journal of Medical Internet Research 18(2): e32.

13. IBM (2006) IBM SPSS Software.

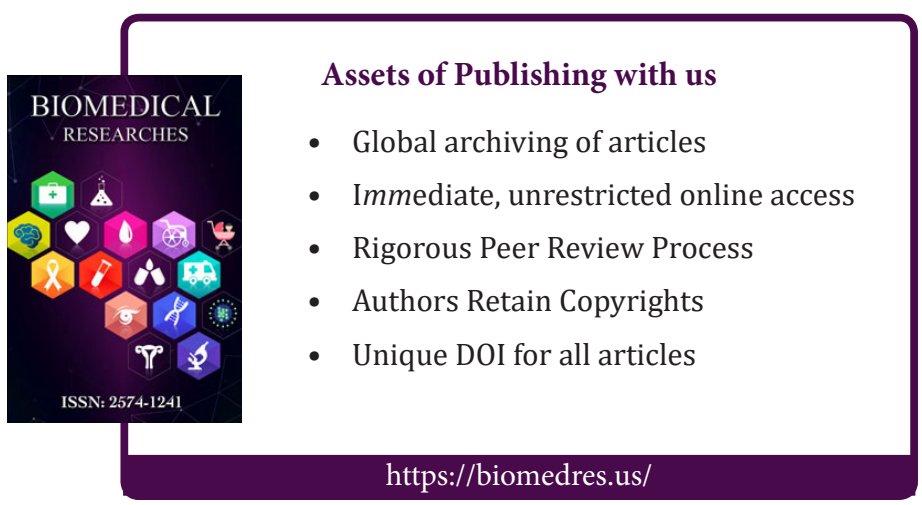

